\title{
Modelling and Simulation of Air Entrainment Period Effect on Prediction of Quasi-dimensional Model for Diesel Engine
}

\author{
Kunpeng Qi ${ }^{1{ }^{1},}$, Wuqiang Long ${ }^{2}$ and Xiaoping Guo ${ }^{2}$ \\ ${ }^{1}$ School of Traffic and Transport Engineering, Dalian Jiao Tong University, Dalian 116028, China \\ ${ }^{2}$ Institute of Internal Combustion Engine, Dalian University of Technology, Dalian 116023, China \\ ${ }^{*}$ Corresponding author
}

\begin{abstract}
In order to improve the precision of quasi-dimensional model for predicting diesel engine performance, three kinds of air entrainment period in quasi-dimensional model for diesel engine working process is developed in this research. The software MATLAB/Simulink is utilized to build the quasi-dimensional model for diesel engine and different kinds of air entrainment period effect on the performance prediction of diesel engine are simulated. The simulation results show that the relative errors of diesel engine performance between three methods are obvious different at rated working condition. It can be concluded that the proper method to calculate air entrainment period must be selected to improve performance prediction precision of simulation model.
\end{abstract}

Keywords- diesel engine; performance prediction; quasidimensional model; MATLAB/Simulink

\section{INTRODUCTION}

Nowadays, in order to satisfy the demands of shortening development period and the diversification of diesel engine products, numerical simulation has been widely used in the development of diesel engine for the sake of efficiency improvement, time-reducing and resource saving[1-2].

In this work, a quasi-dimensional model of diesel engine working process is proposed and the performance parameters for diesel engine are obtained. Additionally, the influence of air entrainment period on the prediction precision of performance parameters for diesel engine simulation model is analyzed.

\section{MODELING OF QUASI-DimenSIONAL MODEL FOR DiEsEl ENGINE WORKING PROCESS}

The quasi-dimensional model for diesel engine working process in this research is divided into six sub-models, namely compression sub-model, combustion sub-model, expansion sub-model, exhaust sub-model, inlet and outlet valve overlap sub-model and intake sub-model [3-4]. The simulation results, which include instantaneous data such as pressure, temperature, mass and performance parameters are obtained by solving the energy conservation equations, the mass conservation equations and the ideal gas state equations.

Meanwhile, different methods are evaluated which apply different air entrainment period. The methods are called as
FICE, BIJT and WJTT respectively. The FICE method assumes that no fresh air is entrained into a combustion zone after combustion is finished. BIJT method assumes that fresh air is still entrained into a combustion zone after the end of combustion, and calculates the quantity of fresh air entrained into the combustion zone by the momentum conservation equations. The air entrainment continues until the temperature of the current combustion zone is less than $1800 \mathrm{~K}$. The calculation principle of WJTT method is similar to BIJT method, but WJTT method takes the temperature of all combustion zones less than $1800 \mathrm{~K}$ as the criteria to determine the stop of air entrainment.

\section{SimUlation OF QUASI-Dimensional MODEL FOR Diesel Engine Working Process}

MATLAB/Simulink was utilized to simulate the quasidimensional model for diesel engine working process. Experimental data were obtained from the 1135 naturally aspirated diesel engine for comparison with the calculated results. The specifications of the diesel engine are listed in Table 1.

TABLE I. SPECIFICATIONS OF THE 1135 DIESEL ENGINE

\begin{tabular}{|lc|c|}
\hline \multicolumn{2}{|c|}{ Parameters } & Value \\
\hline Cylinder bore & $\mathrm{D}$ & $135 \mathrm{~mm}$ \\
\hline Stroke & $\mathrm{S}$ & $150 \mathrm{~mm}$ \\
\hline Compression ratio & $\varepsilon$ & 17 \\
\hline Displacement volume & $\mathrm{V}$ & $2.147 \mathrm{~L}$ \\
\hline Rated power & $\mathrm{Pe}_{\mathrm{e}}$ & $14.7 \mathrm{~kW}$ \\
\hline Rated rotation speed & $\mathrm{n}_{\mathrm{e}}$ & $1500 \mathrm{r} / \mathrm{min}$ \\
\hline Fuel injection advance angle & $\varphi_{\mathrm{i}}$ & $10^{\circ} \mathrm{CA} \mathrm{BTDC}$ \\
\hline Fuel injection duration & $\Delta \varphi_{\mathrm{i}}$ & $18^{\circ} \mathrm{CA}$ \\
\hline
\end{tabular}

\section{A. Validation of Model}

Figure 1 shows the comparisons of calculated results and experimental data of in-cylinder pressure and heat release rate at rated working condition of diesel engine. From Figure 1, it can be seen that the two in-cylinder pressure curves are well 
consistent with each other at rated working condition which indicate that the quasi-dimensional model is validated to be applied to simulate the diesel engine working process.
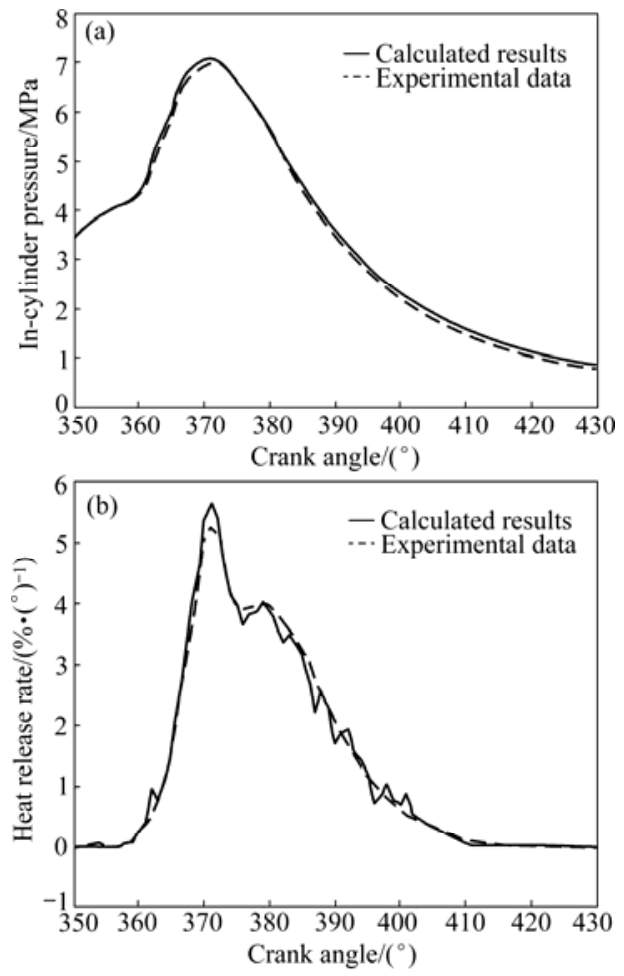

FIGURE I. COMPARISONS OF CALCULATED RESULTS AND EXPERIMENTAL DATA OF IN-CYLINDER PRESSURE (A) AND HEAT RELEASE RATE (B) AT RATED WORKING CONDITION

\section{B. Influence of Air Entrainment Period on Prediction Precision of Simulation Model}

Table 2 shows that the relative error of power and bsfc between experimental data and calculated results is less than $2.5 \%$ at rated working condition for the three methods. Furthermore, the relative error of nitric oxide and soot emissions based on FICE method is less than $5.9 \%$ which is obviously better than the other two methods. The cause of the above differences can be explained by the different calculation criteria of air entrainment period in these three methods. The three methods have the same air entrainment quantity during combustion period, but after combustion period they have different air entrainment quantity. Therefore, the different air entrainment quantity after combustion period, which results in different exposition time of combustion zone under high temperature, leads to bigger discrepancy on the calculation results of nitric oxide and soot emissions among the three methods. The FICE method has the shortest air entrainment period, and accordingly its exposition time of combustion zone under high temperature is the longest. This makes its calculation results of nitric oxide and soot emissions are the highest compared with other two methods and closer to the experimental data.
TABLE II. INFLUENCE OF AIR ENTRAINMENT PERIOD ON PREDICTION PRECISION OF DIESEL ENGINE PERFORMANCE PARAMETERS AT RATED WORKING CONDITION

\begin{tabular}{|c|c|c|c|}
\hline \multirow{2}{*}{ Method } & \multicolumn{3}{|c|}{ Power/kW } \\
\hline & Experimental data & Calculated results & Relative error/\% \\
\hline FICE & \multirow{3}{*}{14.7} & 15.01 & 2.11 \\
\hline BIJT & & 15.05 & 2.38 \\
\hline WJTT & & 15.06 & 2.45 \\
\hline \multirow{2}{*}{ Method } & \multicolumn{3}{|c|}{$\mathbf{B S F C} /\left(\mathbf{g} \bullet \mathbf{k} \mathbf{W}^{-1} \cdot \mathbf{h}^{-1}\right)$} \\
\hline & Experimental data & Calculated results & Relative error/\% \\
\hline FICE & \multirow{3}{*}{245} & 240.0 & 2.04 \\
\hline BIJT & & 239.3 & 2.33 \\
\hline WJTT & & 239.2 & 2.37 \\
\hline \multirow{2}{*}{ Method } & \multicolumn{3}{|c|}{ Nitric oxide emission/ppm } \\
\hline & Experimental data & Calculated results & Relative error/\% \\
\hline FICE & \multirow{3}{*}{1246} & 1176 & 5.62 \\
\hline BIJT & & 1098 & 11.88 \\
\hline WJTT & & 1093 & 12.28 \\
\hline \multirow{2}{*}{ Method } & \multicolumn{3}{|c|}{ Soot emission/BSU } \\
\hline & Experimental data & Calculated results & Relative error/\% \\
\hline FICE & \multirow{3}{*}{1.77} & 1.873 & 5.82 \\
\hline BIJT & & 1.576 & 10.96 \\
\hline WJTT & & 1.573 & 11.13 \\
\hline
\end{tabular}

IV. CONCLUSIONS

1) In this paper, a quasi-dimensional model of diesel engine is proposed. The simulation results of the model have good accordance with experimental data which proves the validation of this model.

2) It is important to select proper calculation method of air entrainment period for the purpose of improving perfomance prediction precision of the simulation model.

\section{ACKNOWLEDGMENT}

This research was financially supported by the National Science Foundation (No. 51579041), China.

\section{REFERENCES}

[1] Berber A, Tinkir M, Gultekin S S, Celikten I, "Prediction of a diesel engine characteristics by using different modelling techniques." Int $\mathrm{J}$ Phys Sci, 2011, vol 6, pp 3979-3992.

[2] Morteza Ghorbani, Sasan Akbarpour, "The multi-zone model of the low heat rejection engine for DI diesel injection engines”, J Braz. Soc. Mech. Sci. Eng.,2016,38, pp 365-375.

[3] Qi, K.P., Feng, L.Y., Leng, X.Y., Du, B.G. and Long, W.Q., "Simulation of quasi-dimensional combustion model for predicting diesel engine performance”. Applied Mathematical Modelling, 2011, 35(2), pp.930940 .

[4] Qi, K.P., Feng, L.Y., Leng, X.Y., Tian, J.P. and Long, W.Q., "Simulation of quasi-dimensional model for diesel engine working process". Journal of Central South University of Technology, 2010, 17(4), pp.868-872. 